\title{
Prevalence of sub clinical hypothyroidism and pregnancy outcome: a prospective comparative study
}

\author{
Bilal Ur Rehman*, Hiba Gull
}

Department of Obstetrics and Gynaecology, Maternity Hospital, SKIMS, Soura, Srinagar, Jammu and Kashmir, India

Received: 28 June 2019

Revised: 01 February 2020

Accepted: 05 February 2020

\section{*Correspondence:}

Dr. Bilal Ur Rehman,

E-mail: drbilalurrehman@gmail.com

Copyright: (c) the author(s), publisher and licensee Medip Academy. This is an open-access article distributed under the terms of the Creative Commons Attribution Non-Commercial License, which permits unrestricted non-commercial use, distribution, and reproduction in any medium, provided the original work is properly cited.

\begin{abstract}
Background: In pregnancy, subclinical hypothyroidism is more common than overt hypothyroidism, ranging from $15 \%$ to $28 \%$ in Iodine sufficient region. Evidence suggests that subclinical hypothyroidism is associated with adverse pregnancy outcome. The aim of this study was to find the prevalence of subclinical hypothyroidism in pregnant women and adverse pregnancy outcome.

Methods: This hospital based prospective comparative study was conducted over a period of 6 months from $1^{\text {st }}$ July 2018 to $31^{\text {st }}$ December 2018 in department of obstetrics and gynecology SKIMS Soura Kashmir. All the subjects who fulfilled the inclusion criteria and who consented to participate were screened for subclinical hypothyroidism.

Results: A total of 175 pregnant women participated in the study and subclinical hypothyroidism was diagnosed in 25 pregnant women $(14.2 \%)$. Most of our patients were in age group 21 to 30 years $(69.1 \%)$. Pregnant women with subclinical hypothyroidism had significant risk of preeclampsia (35\%) and higher cesarean section rate $(29.6 \%)$. Neonate of women with subclinical hypothyroidism had higher incidence poor Apgar score, NICU admission.

Conclusions: The prevalence of subclinical hypothyroidism is high in pregnant women and the gravity of the complications like pre-eclampsia, neonate with low Apgar score, increased NICU admission, overweight the cost of screening. In this view, we propose screening of all pregnant women in the first trimester for diagnosis.
\end{abstract}

Keywords: Fetal outcome, Maternal outcome, Prevalence, Subclinical hypothyroidism

\section{INTRODUCTION}

Subclinical hypothyroidism $(\mathrm{SCH})$ is the commonest form of hypothyroidism in pregnancy. SCH is defined by a normal free thyroxine in the presence of an elevated thyroid stimulating hormone (TSH). ${ }^{1}$ Recently, the normal range TSH during pregnancy was redefined to an upper limit of $2.5 \mathrm{mIU} / \mathrm{L}$ during the first trimester and 3.0 $\mathrm{mIU} / \mathrm{L}$ during the second and third trimester. ${ }^{2}$

Applying the current diagnostic criteria, 15\% of pregnant women in the United States have $\mathrm{SCH}$, a fivefold increase in the prevalence of $\mathrm{SCH} .{ }^{3}$ The effects of subclinical hypothyroidism in pregnancy include increased incidence of premature birth, placental abruption, low birth weight, low Apgar score, increased need for caesarean, hypertension in mothers increased neonatal mortality and neuropsychiatric abnormalities in children., ${ }^{4,5}$ In comparison with overt hypothyroidism where there is clear evidence for adverse events, the impact of SCH on pregnancy is unclear. ${ }^{6}$ There have been numerous retrospective studies reporting associations between SCH And adverse pregnancy outcome, however, the data is inconsistent, with many studies failing to demonstrate an adverse effect from untreated $\mathrm{SCH}$ in India. Hence this study was undertaken to estimate the prevalence of SCH and find out the pregnancy outcome in women with $\mathrm{SCH}$. 


\section{METHODS}

This is hospital-based prospective comparative study conducted from $1^{\text {st }}$ July 2018 to $31^{\text {st }}$ December 2018 in department of obstetrics and gynecology SKIMS Soura Kashmir. After obtaining informed consent, a total number of 175 pregnant women were selected during the study period. A minimum Sample size of 169.2 was calculated with an anticipated prevalence of subclinical hypothyroidism during pregnancy in females of Kashmir, India was $12.6 \%$ women. ${ }^{8}$ Using the statistical formula.

$$
n=z^{2} p(1-p) / e^{2}
$$

$\mathrm{n}=$ Sample size, $\mathrm{z}=$ level of confidence of $95 \%$ (1.96), $\mathrm{p}$ $=$ prevalence $(11 \%), \mathrm{e}=$ margin of error $(5 \%)$. Thyroid profile (TSH, FT4 and FT3) was done during their first visit and in subsequent trimester based on inclusion and exclusion criteria

\section{Inclusion criteria}

- $\mathrm{TSH}>2.5 \mathrm{mIU} / \mathrm{l}$ in $1^{\text {st }}$ trimester

- $\mathrm{TSH}>3 \mathrm{mIU} / \mathrm{l}$ in $2^{\text {nd }}$ and $3^{\text {rd }}$ trimester

- $\quad$ Normal FT4 and FT3.

\section{Exclusion criteria}

- Pre-existing thyroid disorder

- Other medical problem like chronic hypertension, seizure disorder, T2DM etc.

The study population was divided into two groups, case and control. All the patients were followed up for maternal complications (pregnancy induced hypertension,
Anemia), fetal complications (preterm birth), mode of delivery (vaginal, caesarean) and neonatal complications (Apgar score at $1 \mathrm{~min}$. and NICU admission).

\section{Statistical analysis}

After collecting data in prescribed form, data entry and analysis was done using SPSS vs 20 program. Chi-square test and other appropriate statistical test were done. Pvalue less than 0.05 were considered statistically significant.

\section{RESULTS}

Out of 175 pregnant women, subclinical hypothyroidism was diagnosed in 25 pregnant women. The prevalence of $\mathrm{SCH}$ in the study population was $(14.2 \%)$ as shown in Table 1

Most of our patients were in the age group of 21-30 years $(69.1 \%)$. In the study group $11.1 \%$ of $\mathrm{SCH}$ women belonged to age group $\leq 20$ years, $12.4 \%$ belonged to age group 21-30 years and $22.2 \%$ belonged to age group 3140 years. Incidence of SCH increases as the age increases but the relation was statistically insignificant. The $p$ value was $>0.05$ (Table 2)

Table 1: Distribution of subclinical hypothyroidism in study subject.

\begin{tabular}{|ll|}
\hline $\begin{array}{l}\text { Distribution of subclinical } \\
\text { hypothyroidism subjects by }\end{array}$ & $\begin{array}{l}\text { No. of study } \\
\text { subjects }\end{array}$ \\
\hline Present & $25(14.3 \%)$ \\
\hline Absent & $150(85.7 \%)$ \\
\hline Total & $175(100 \%)$ \\
\hline
\end{tabular}

Table 2: Distribution of subclinical hypothyroidism by age.

\begin{tabular}{|c|c|c|c|c|c|}
\hline Subclinical hypothyroidism & $\leq 20$ years & 21-30 years & $31-40$ years & Total & p value \\
\hline Present & $02(11.1 \%)$ & $15(12.4 \%)$ & $08(22.2 \%)$ & $25(14.3 \%)$ & \multirow{3}{*}{0.30} \\
\hline Absent & $16(88.9 \%)$ & $106(87.6 \%)$ & $28(77.8 \%)$ & $150(85.7 \%)$ & \\
\hline Total & $18(10.2 \%)$ & $121(69.1 \%)$ & $36(20.5 \%)$ & $175(100 \%)$ & \\
\hline
\end{tabular}

Chi-Square value: 2.35 ; degree of freedom: 2 .

Table 3: Distribution of subclinical hypothyroidism by haemoglobin levels.

\begin{tabular}{|llll|}
\hline Haemoglobin level & \multicolumn{2}{l}{ Sub clinical hypothyroidism } & Total \\
\hline & Present & Absent & \\
\hline$<10 \mathrm{~g} / \mathrm{dl}$ & $6(13 \%)$ & $40(87 \%)$ & $46(100 \%)$ \\
\hline $10-10.9 \mathrm{~g} / \mathrm{dl}$ & $8(14.8 \%)$ & $46(85.2 \%)$ & $54(100 \%)$ \\
\hline $11 \mathrm{~g} / \mathrm{dl}$ or more & $11(14.7 \%)$ & $64(85.3 \%)$ & $75(100 \%)$ \\
\hline Total & $25(14.3 \%)$ & $150(85.7 \%)$ & $175(100 \%)$ \\
\hline
\end{tabular}

Chi-Square value: 0.079; degree of freedom: 1 .

WHO has defined hemoglobin of less than $11 \mathrm{gm} \%$ as anemia in pregnancy. In our study pregnant women with SCH $14(14 \%)$ cases had anemia compared to patient without SCH 68 (68\%). The difference was statistically insignificant, $\mathrm{p}$ value is $>0.05$ (Table 3 ). Compared with euthyroid pregnant women, pregnant women with $\mathrm{SCH}$ 
had a higher risk of preeclampsia. The $\mathrm{p}$ value is $<0.05$. The relation was statistically significant (Table 4 ).

Risk of prematurity was more in $\mathrm{SCH}$ patient than euthyroid pregnant women (Table 5). The relation was statistically insignificant. The $\mathrm{p}$ value was $>0.5$.
In our study normal delivery occurred in 9 (7.4\%), caesarean deliveries in $16(29.6 \%)$ and as compared to euthyroid pregnant women in whom normal deliveries were $112(92.6 \%)$, caesarean deliveries in $38(70.4 \%)$ (Table 6). This observation was statistically significant with a $\mathrm{p}$ value of $<0.05$.

Table 4: Distribution of subclinical hypothyroidism by preeclampsia.

\begin{tabular}{|c|c|c|c|c|}
\hline Preeclampsia & Subclinical & & Total & p value \\
\hline & Present & Absent & & \multirow{4}{*}{0.004} \\
\hline Yes & $7(35 \%)$ & $13(65 \%)$ & $20(100 \%)$ & \\
\hline No & $18(11.6 \%)$ & $137(88.4 \%)$ & $155(100 \%)$ & \\
\hline Total & $25(14.3 \%)$ & $150(85.7 \%)$ & $175(100 \%)$ & \\
\hline
\end{tabular}

Chi-Square value: 7.91; degree of freedom: 1 .

Table 5: Distribution of subclinical hypothyroidism by prematurity.

\begin{tabular}{|c|c|c|c|c|}
\hline Prematurity & Subclinical & & Total & p value \\
\hline & Present & Absent & & \multirow{4}{*}{0.5083} \\
\hline Yes & $3(20 \%)$ & $12(80 \%)$ & $15(100 \%)$ & \\
\hline No & $22(13.7 \%)$ & $138(86.3 \%)$ & $160(100 \%)$ & \\
\hline Total & $25(14.3 \%)$ & $150(85.7 \%)$ & $175(100 \%)$ & \\
\hline
\end{tabular}

Chi-Square value: 7.91; degree of freedom: 1 .

Table 6: Distribution of subclinical hypothyroidism subjects by mode of delivery.

\begin{tabular}{|c|c|c|c|c|}
\hline Mode of delivery & Subclinical & & Total & p value \\
\hline & Present & Absent & & \multirow{4}{*}{0.0000} \\
\hline FTND & $9(7.4 \%)$ & $112(92.6 \%)$ & $121(100 \%)$ & \\
\hline LSCS & $16(29.6 \%)$ & $38(70.4 \%)$ & $54(100 \%)$ & \\
\hline Total & $25(14.3 \%)$ & $150(85.7 \%)$ & $175(100 \%)$ & \\
\hline
\end{tabular}

Chi-Square value: 15.01; degree of freedom: 1 .

Table 7: Distribution of subclinical hypothyroidism by birth weight.

\begin{tabular}{|c|c|c|c|c|}
\hline Birth weight & \multicolumn{2}{|c|}{ Subclinical hypothyroidism } & Total & p value \\
\hline & Present & Absent & & \multirow{5}{*}{0.5032} \\
\hline $1500-1999 \mathrm{~g}$ & $2(13.3 \%)$ & $13(86.7 \%)$ & $15(100 \%)$ & \\
\hline $2000-2400$ & $7(20.6 \%)$ & $27(79.4 \%)$ & $34(100 \%)$ & \\
\hline 2400 -or more & $16(12.7 \%)$ & $110(87.3 \%)$ & $126(100 \%)$ & \\
\hline Total & $25(14.3 \%)$ & $150(85.7 \%)$ & $175(100 \%)$ & \\
\hline
\end{tabular}

Chi-Square value: 1.373; degree of freedom: 2 .

Table 8: Distribution of subclinical hypothyroidism by Apgar score.

\begin{tabular}{|c|c|c|c|c|}
\hline Apgar score at $1 \mathrm{~min}$ & \multicolumn{2}{|c|}{ Subclinical hypothyroidism } & Total & p value \\
\hline & Present & Absent & & \\
\hline$<7$ & $5(62.5 \%)$ & $3(27.5 \%)$ & $8(100 \%)$ & \\
\hline 7 or more & $20(12 \%)$ & $147(88 \%)$ & $167(100 \%)$ & 0.00000 \\
\hline Total & $25(14.3 \%)$ & $150(85.7 \%)$ & $175(100 \%)$ & \\
\hline
\end{tabular}

Chi-Square value: 15.91; degree of freedom: 1.

The incidence of LBW 1.5-1.999 kg and 2.0-2.4 kg was 2 $(13.3 \%)$ and $7(20.6 \%)$ in $\mathrm{SCH}$ patient as compared to 13
$(86.7 \%)$ and $27(79.4 \%)$ in euthyroid patients. The relation was statistically insignificant (Table 7). 
Low Apgar score was more in $\mathrm{SCH}$ patient than euthyroid patients with incidence of $62.5 \%$ (Table 8). p value was $<0.05$. The relation was statistically significant.
NICU admission was more in babies born to $\mathrm{SCH}$ patients than euthyroid pregnant women with incidence of $66.7 \%$ (Table 9). $\mathrm{p}$ value was $<0.05$. The relation was statistically significant.

Table 9: Distribution of subclinical hypothyroidism by NICU admission.

\begin{tabular}{|c|c|c|c|c|}
\hline NICU admission & Subclinical & & Total & p value \\
\hline & Present & Absent & & \\
\hline Yes & $4(66.7 \%)$ & $2(33.3 \%)$ & $6(100 \%)$ & \multirow{3}{*}{0.00008} \\
\hline No & $21(30.4 \%)$ & $148(87.6 \%)$ & $169(100 \%)$ & \\
\hline Total & $25(14.3 \%)$ & $150(85.7 \%)$ & $175(100 \%)$ & \\
\hline
\end{tabular}

Chi-Square value: 13.92; degree of freedom: 1 .

\section{DISCUSSION}

The study was done to find out the prevalence and pregnancy outcome in patients with subclinical hypothyroidism in department of obstetrics and gynecology Maternity Hospital, Sher-i-Kashmir Institute of Medical Sciences (SKIMS), Soura, Srinagar, J\&K, India. The study was conducted in 175 patients taken by simple random sampling. All the subjects who fulfilled the inclusion criteria and who consented to participate were screened for subclinical hypothyroidism. Out of 175 pregnant women, subclinical hypothyroidism was diagnosed in 25 pregnant women. The prevalence of SCH in our study population was (14.2\%) which was comparable to study done by Mukhtar B et al (12.6\%). ${ }^{7}$ Most of our patients were in the age group of 18-40 years (69.1\%). The age group selected by Ablovich et al, was again in range of 16-39 years, which is in concordance with our studied population. ${ }^{8}$ In the study group $11.1 \%$ of $\mathrm{SCH}$ pregnant women belonged to age group $\leq 20$ years, $12.4 \%$ belonged to age group 21-30 years and $22.2 \%$ belonged to age group 31-40 years. Incidence of $\mathrm{SCH}$ increases as the age increased but the relation was statistically insignificant. Similar association was seen in the study done by Potlukova E et al. ${ }^{9}$ The incidence of anemia in pregnant women with subclinical hypothyroidism was less as compared to euthyroid patient. Difference was statistically insignificant. Similar association had been seen in study done by Sannaboraiah A et al, compared with euthyroid pregnant women, pregnant women with $\mathrm{SCH}$ had a higher risk of preeclampsia. ${ }^{10}$ The relation was statistically significant. A similar association has been found in the study done by Wilson et al, there was a statistically significant association between thyroid disorders and the risk of PIH, mild to severe pre-eclampsia. ${ }^{11}$ Risk of prematurity was more in SCH patient than euthyroid pregnant women but the relation was statistically insignificant. Same was seen in study done by Sannaborraiah A et al. ${ }^{10}$ In our study caesarean deliveries was significantly higher in $\mathrm{SCH}$ pregnant women compared to euthyroid pregnant women. This observation was statistically significant. Sannaborraiah A et al had shown similar results i.e., cesarean section rate was statistically higher among pregnant women with subclinical hypothyroidism. ${ }^{10}$ The incidence of LBW was less in SCH pregnant patient compared to euthyroid patients. The relation was statistically insignificant. A similar association has been seen in study done by Sharma et al. ${ }^{12}$ Neonate with low Apgar score was significantly higher in $\mathrm{SCH}$ mothers than euthyroid mothers. A similar association has been seen in study done by Saki F et al. ${ }^{13}$ NICU admission was significantly more in babies born to $\mathrm{SCH}$ patients than euthyroid pregnant women. Keeping in mind the high prevalence of subclinical hypothyroidism in our state and considering, as already established, that low maternal thyroxine levels increases incidence of preeclampsia, neonate with low Apgar score, increased NICU admission. Therefore, it becomes mandatory to screen all pregnant women and start with levothyroxine therapy in pregnant females with even slightly raised TSH.

\section{CONCLUSION}

The present study has identified that the prevalence of subclinical hypothyroidism in pregnant female was increased and there was significant difference in the development of pre-eclampsia, increased caesarean section rate, neonate of low Apgar score, increased NICU admission between pregnant women having subclinical hypothyroidism and euthyroid pregnant women. It was therefore concluded that thyroid function test should be done in each pregnant women to detect subclinical hypothyroidism so that timely intervention can be done to prevent pregnancy related complications.

\section{Funding: No funding sources \\ Conflict of interest: None declared}

Ethical approval: The study was approved by the Institutional Ethics Committee

\section{REFERENCES}

1. Alexander EK, Pearce EN, Brent GA, Brown RS, Chen H, Dosiou C, et al. 2017 Guidelines of the American Thyroid Association for the diagnosis and 
management of thyroid disease during pregnancy and the postpartum. Thyroid. 2017;27(3):315-89.

2. Stagnaro-Green A, Abalovich M, Alexander E, Azizi F, Mestman J, Negro R, et al. Guidelines of the American Thyroid Association for the diagnosis and management of thyroid disease during pregnancy and postpartum. Thyroid. 2011;21:1081-125.

3. Blatt AJ, Nakamoto JM, Kaufman HW. National status of testing for hypothyroidism during pregnancy and postpartum. J Clin Endocrinol Metab. 2012;97:777-84.

4. Allan WC, Haddow JE, Palomaki GE, Williams JR, Mitchell ML, Hermos RJ, et al. Maternal thyroid deficiency and pregnancy complications: implications for population screening. J Med Scree. 2000;7(3):127-30.

5. Allan WC, Haddow JE, Palomaki GE, Williams JR, Mitchell ML, Hermos RJ, et al. Maternal thyroid deficiency and pregnancy complication: Implications for population screening. J Med Scree. 2000;7:12730 .

6. Negro R, Stagnaro-Green A. Diagnosis and management of subclinical hypothyroidism in pregnancy. BMJ. 2014;349:g4929.

7. Mukhtar B, Kamili MMA, Habib O. Prevalence of subclinical hypothyroidism in pregnant females of Kashmir, India. Pulsus J Surg Res. 2017;1:11-4.

8. Abalovich M, Gutierrez S, Alcaraz G, Maccallini G, Garcia A, Levalle O. Overt and subclinical hypothyroidism complicating pregnancy. Thyroid. 2002;12(1):63-8.
9. Potlukova E, Potluka O, Jiskra J, Limanova Z, Telicka Z, Bartakova J. Drahomira Spring; Is age a risk factor for hypothyroidism in pregnancy? An Analysis of 5223 pregnant women. J Clin Endocrinol Metabol. 2012;97(6):1945-52.

10. Sannaboraiah A, Upadhyaya R, Garag S, Krishnappa S. Subclinical hypothyroidism in pregnancy and outcomes. Int J Reprod Contracept Obstet Gynecol. 2017;6:1215-21.

11. Wilson KL, Casey BM, Mclntire DD, Halvorson LM, Cunningham FG. Subclinical thyroid disease and the incidence of hypertension in pregnancy. Obstet Gynecol. 2012;119:315-20.

12. Sharma D, Dixit PV, Gavit Y. Maternal and perinatal outcome in hypothyroidism in pregnancy: a prospective observational study. Int $\mathbf{J}$ Reprod Contracept Obstet Gynecol. 2017;6:5548-53.

13. Saki F, Dabbaghmanesh MH, Ghaemi SZ, Forouhari S, Ranjbar Omrani G, Bakhshayeshkaram M. Thyroid function in pregnancy and its influences on maternal and fetal outcomes. Int J Endocrinol Metab. 2014;12(4):e19378.

Cite this article as: Rehman BU, Gull H. Prevalence of sub clinical hypothyroidism and pregnancy outcome: a prospective comparative study. Int J Reprod Contracept Obstet Gynecol 2020;9:1250-4. 